\title{
Changing paradigm in treatment of lung cancer
}

\author{
Sundaram Viswanath, Abhishek Pathak, Amul Kapoor, Anvesh Rathore, Bhupendra Nath Kapur \\ Medical Oncology, Army Hospital Research and Referral, New Delhi 110010, India.
}

Correspondence to: Dr. Abhishek Pathak, Medical Oncology, Army Hospital Research and Referral, New Delhi 110010, India.

E-mail: drabhipat@gmail.com

\section{A B S T R A C T}

Lung cancer is one of the most common and deadliest forms of cancer. It accounts for $13 \%$ of all new cancer cases and $19 \%$ of cancer-related deaths. In India, lung cancer constitutes $6.9 \%$ of all new cancer cases and $9.3 \%$ of all cancer cases. There has also been a dramatic rise worldwide in both the absolute and relative frequencies of lung cancer occurrence. In 1953 it became the most common cause of cancer mortality in men. By 1985, it became the leading cause of cancer deaths in women, causing almost twice as many deaths as breast cancer. The demographic profile of lung cancer has changed greatly over the years; however, methods for diagnosing, screening, and managing lung cancer patients have improved. This is due to our growing understanding of the biology of lung cancer. It is now possible to further define lung cancer types beyond small cell lung carcinoma and non-small cell lung carcinoma. Moreover, new histology-based therapeutic modalities have been developed, and more new lung cancer biomarkers have been uncovered. Therefore, more detailed histological characterization of lung cancer samples is warranted in order to determine the best course of treatment for specific patients. This review article describes how these new molecular technologies are shaping the way lung cancer can be treated in future.

Key words: Non-small cell lung carcinoma; epidermal growth factor receptor; anaplastic lymphoma kinase

\section{INTRODUCTION}

Lung cancer is one of the most common and deadliest forms of cancer. Worldwide, it accounts for $13 \%$ of all new cancer cases and $19 \%$ of cancer-related deaths. In India alone, lung cancer constitutes $6.9 \%$ of all new cancer cases and $9.3 \%$ of all cancer-related deaths. There has been a dramatic rise worldwide in both the absolute and relative frequencies of lung cancer occurrence. ${ }^{[1]}$ By 1953, lung cancer was the most common cause of cancer mortality in men. By 1985, it was the leading cause of cancer deaths in women, causing almost twice as many deaths as breast cancer. ${ }^{[2]}$

The demographic profile of lung cancer has changed greatly over the years; however, methods for diagnosing, screening and managing lung cancer patients have also improved. This is due to our growing understanding of the biology of lung cancer. It is now possible to further define lung cancer types beyond small cell lung carcinoma (SCLC) and nonsmall cell lung carcinoma (NSCLC). In 2012, the Cancer Genome Atlas (TCGA) Research Network published in Nature that characterized the lung squamous cell carcinoma

\begin{tabular}{|l|l|}
\hline \multicolumn{3}{|c|}{ Access this article online } \\
\hline Quick Response Code: & Website: \\
& http://www.jcmtjournal.com \\
\cline { 2 - 2 } & \\
\hline
\end{tabular}

genome. The researchers found a large number and variety of DNA alterations, many of which seem to be the driving force behind the initiation and progression of lung cancer. TCGA is jointly funded and managed by the National Human Genome Research Institute (NHGRI) and the National Cancer Institute (NCI), both of which are part of the National Institutes of Health. New histology-based therapeutic modalities have been developed, and more new lung cancer biomarkers have been uncovered. As a result, more detailed histological characterization of lung cancer samples is warranted in order to determine the best course of treatment for specific patients. ${ }^{[3]}$

For NSCLC, there are currently more than $50 \%$ of adenocarcinoma cases and around $15-20 \%$ of squamous cell carcinoma cases that need to be further characterized based on mutation analysis. Mutations in epidermal growth factor receptor (EGFR) gene strongly predict the efficacy of EGFR inhibitors, with response rates of over $70 \%$ in patients who have EGFR mutations. ${ }^{[4]}$ In

This is an open access article distributed under the terms of the Creative Commons Attribution-NonCommercial-ShareAlike 3.0 License, which allows others to remix, tweak, and build upon the work non-commercially, as long as the author is credited and the new creations are licensed under the identical terms.

For reprints contact: service@oaepublish.com

How to cite this article: Viswanath S, Pathak A, Kapoor A, Rathore $\mathrm{A}$, Kapur BN. Changing paradigm in treatment of lung cancer. $\mathrm{J}$ Cancer Metasta Treat 2016;2:214-9.

Received: 05-12-2015; Accepted: 17-03-2016 
two randomized phase III studies, the Iressa Pan-Asia Study (IPAS) and WJTOG3405, the use of gefitinib as the first-line treatment for previously untreated metastatic adenocarcinoma of the lung leads to longer progressionfree survival (PFS) in patients with tumors positive for EGFR mutations, compared to platinum-based doublet chemotherapy. ${ }^{[5]}$ Similar outcomes have been observed for erlotinib in advanced NSCLC patients with EGFR mutations. ${ }^{[6]}$ These findings have important implications to lung cancer treatment regimes in India, where EGFR mutations have been shown to occur in $25-50 \%$ of lung cancer cases. ${ }^{[7]}$ However, the purpose of mutational studies in adenocarcinoma and squamous cell carcinoma can be very different. Researchers have made important progress in the understanding and development of treatments for adenocarcinomas, which are the most common type of lung cancer. Unfortunately, these treatments have been largely ineffective in treating lung squamous cell carcinomas. Lung squamous cell carcinomas frequently develop in the large airways in the centre of the lungs, while adenocarcinomas often arise at the edges of the lungs. Lung adenocarcinomas sometimes affect non-smokers, while lung squamous cell carcinomas arise almost exclusively in smokers.

Another example of mutation-driven therapy is the targeting of the echinoderm microtubule-associated protein like 4-anaplastic lymphoma kinase (EML4ALK) rearrangement. The ALK gene encodes anaplastic lymphoma kinase, a member of the receptor tyrosine kinase (RTK) family. RTKs transmit signals from the cell surface into the cell through a process called signal transduction. The EML-ALK fusion leads to uncontrolled cell proliferation. This mutation occurs in about $3-7 \%$ of unselected NSCLC. ${ }^{[8]}$ In one study, NSCLC patients treated with crizotinib, a tyrosine kinase inhibitor targeting ALK, showed a response rate of $65 \% .{ }^{[9]}$ In cases where there was disease progression after treatment with crizotinib, ceritinib can be used. Ceritinib is a new ALK inhibitor that has been recently approved based on its encouraging response rate of $56 \%$ in patients whose cancer has progressed after treatment with crizotinib.

\section{MOLECULAR TESTING}

The most useful biomarkers for predicting the efficacy of targeted therapy in advanced NSCLC are somatic genome alterations known as driver mutations. These mutations occur in cancer cells in genes encoding proteins that are critical to cell growth and survival. Driver mutations are typically transformative, which means that they initiate the evolution of a non-cancerous cell to a cancerous one. In addition, driver mutations often impart an oncogene addiction trait to the transformed cell. This means that the mutated protein enables the cancer cell to receive survival signals from the driver mutations. Hence, driver mutations are good biomarkers for selecting patients for targeted therapies. Whenever feasible, patients with advanced NSCLC should have their tumours assessed for the presence of driver mutations. ${ }^{[10]}$ Guidelines by the College of American Pathologists (CAP), the International Association for the Study of Lung Cancer (IASLC), and the Association of Molecular Pathologists (AMP) recommend analysis of either the primary tumour or of a metastasis for EGFR and ALK mutations for all patients with tumours that exhibit features of an adenocarcinoma, regardless of their clinical characteristics. ${ }^{[11]}$

The most important requirements for molecular testing modalities are that they should utilise clinically available specimens (formalin- or paraffin-embedded tissue) and that the turnaround time should be relatively short. The instrument should be semi-automated and relatively inexpensive. The most commonly used modalities are: (1) gene sequencing, the most comprehensive method for mutation testing; (2) next-generation sequencing, which uses simultaneous evaluation of multiple genes or even whole genomes; (3) allele-specific testing, which analyzes DNA for a predefined abnormality; (4) mass spectrometry, which analyzes short fragments of DNA by their mass to charge ratio and can detect fragments that have different molecular weights than expected, a mutation; (5) fluorescence in situ hybridisation (FISH), which is typically used to detect gene translocations, amplifications, and other rearrangements; (6) immunohistochemistry (IHC), which is considered an alternative to FISH for determining ALK translocations; and (7) multiplex genotype testing, which allows an entire panel of genotypes of interest to be queried at a single time from a single tissue sample instead of doing the tests sequentially. IHC is, however, not currently recommended for detecting EGFR driver mutations since positive or negative IHC results do not necessarily indicate the presence or absence, respectively, of an EGFR mutation. In contrast, multiplex genotype testing is the most tissue-efficient approach, particularly when dealing with small tumour samples.

\section{Mutations associated}

The identification of oncogenic activation of particular tyrosine kinases in some advanced NSCLC tumours, most notably mutations in the EGFR gene or rearrangements in of the ALK gene, has led to a paradigm shift and the development of specific molecular treatments for patients.

\section{EGFR mutations}

EGFR is a transmembrane protein with cytoplasmic kinase activity that transduces growth signals to the cell. Among Asians, the incidence of EGFR mutation is much higher, up to $62 \%$, and occurs more frequently among non-smokers. In advanced NSCLC, the presence of an EGFR mutation confers a favourable prognosis and is strongly indicative of sensitivity to EGFR tyrosine kinase inhibitors such as erlotinib, gefitinib, and afatinib.

Nevertheless, it has been observed that most of the patients who initially respond to an EGFR tyrosine kinase inhibitor 
subsequently experience a recurrence. How this acquired resistance towards tyrosine kinase inhibitors occurs is not fully understood, but secondary mutations in EGFR and amplification of the oncogene MET are common in these patients. The most common secondary EGFR mutation is the substitution of methionine for threonine at position 790 (T790M). ${ }^{[12]}$ Another characteristic of the acquired resistance is the amplification of the MET oncogene, which is detected in $5-20 \%$ of patients with progressive disease while being treated with either erlotinib or gefitinib. ${ }^{[13]}$ In some cases, only MET amplification is present, while in others, amplification and the secondary T790M mutation in EGFR are present. The absence of the MET oncogene amplification may be indicative of improved survival in patients with surgically resected NSCLC. ${ }^{[14]}$

\section{ALK translocation}

Translocations involving ALK are present in approximately $4 \%$ of NSCLC adenocarcinomas in the United States, and occur more frequently in non-smokers and younger patients. In advanced NSCLC, the presence of an ALK translocation indicates sensitivity to ALK tyrosine kinase inhibitors such as crizotinib and ceritinib, and treatment with these agents significantly prolongs progression-free survival.

\section{RAS mutations}

Approximately 15-25\% of patients withlungadenocarcinoma have oncogenic KRAS mutations. The RAS family of proteins is a central mediator for the mitogen-activated protein kinase (MAPK), signal transducer and activator of transcription (STAT), and phosphoinositide 3-kinase (PI3K) signalling pathways, which work together to control cell proliferation and apoptosis. The most common RAS mutation are missense substitutions in codons 12, 13, or 61 . These mutations result in a constitutively active RAS due to malfunctioning of the RAS GTPase.

\section{ROS1 translocation}

ROS1 translocation is associated with adenocarcinoma histology, and is typically observed in younger patients and those who have never smoked. ROS1 is a RTK of the insulin receptor family. For these patients, first-line management with crizotinib is recommended, instead of platinum-based chemotherapy (Grade 1B). For patients who have received prior chemotherapy, treatment with crizotinib the preferred second-line chemotherapy (Grade 1A). ${ }^{[15]}$

\section{HER2 mutation}

HER2 (ERBB2) encodes a RTK from the EGFR family. Mutations in HER2 have been detected in approximately $1-2 \%$ of NSCLC tumours, primarily adenocarcinomas. For patients with a HER2 exon 20 insertion mutation, a secondline targeted therapy with either afatinib monotherapy or trastuzumab in combination with singl- agent chemotherapy (vinorelbine or docetaxel) is recommended, rather than single-agent chemotherapy alone (Grade 2C). ${ }^{[16]}$

\section{BRAF mutation}

BRAF encodes a downstream signalling mediator of KRAS. The BRAF protein activates the MAPK pathway. BRAF mutations have been observed in $1-3 \%$ of NSCLC with adenocarcinoma variant and are usually associated with a history of smoking. ${ }^{[17]}$ For patients with a BRAF V600E mutation, treatment with BRAF inhibitors such as (dabrafenib andovemurafenib, or dabrafenib plus trametinib to inhibit the MAPK pathway is recommended, rather than single-agent chemotherapy.

\section{MET abnormalities}

Generally smoking-related and identified via IHC in 25-50\% of NSCLC specimens, MET expression also appears to be associated with a more severe prognosis. ${ }^{[18]}$ MET encodes a RTK for hepatocyte growth factor (HGF). Abnormalities include overexpression due to gene amplification and splice site alterations at exon 14 of the gene. In such patients, treatment with a MET inhibitor (crizotinib or cabozantinib) is recommended rather than single-agent chemotherapy as second-line treatment.

\section{RET translocation}

The RET gene encodes a cell surface RTK that is frequently altered in medullary thyroid cancer. RET mutations are encountered in younger patients and non-smokers. For patients with RET rearrangements, treatment with a RET inhibitor such as cabozantinib or vandetanib is recommended rather than single-agent chemotherapy as second-line treatment (Grade 2C). ${ }^{[18]}$

\section{PIK3CA, AKT1, PTEN alterations}

PIK3CA encodes the catalytic subunit of phosphatidyl 3-kinase (PI3K), which is an intracellular central mediator of cell survival signals. AKT1 acts immediately downstream of PI3K. PTEN dephosphorylates and subsequently inhibits AKT. Oncogenic alterations in this pathway include gainof-function mutations in PIK3CA and AKT1, and loss of PTEN function. Alterations in the PI3K signalling pathway appear more frequently in patients who are smokers and with tumours of squamous histology. PIK3CA mutations also may promote resistance to EGFR inhibitors in EGFRmutant NSCLC. ${ }^{[19]}$

\section{FGFR1 amplification}

Fibroblast growth factor receptor-1 (FGFR1) is a cell surface RTK that mediates cell survival and proliferation. FGFR1 amplification has been detected in $13-25 \%$ of squamous tumours. ${ }^{[20]}$ FGFR1 amplification is associated with smoking and with worse overall survival.

\section{CTNNB1 ( $\beta$-catenin) mutation}

The CTNNB1 gene encodes $\beta$-catenin, a protein important for the regulation of epithelial cell growth. Mutations in this gene have been observed in approximately $2 \%$ of NSCLC, particularly in tumours with secondary EGFR mutations following acquired resistance to EGFR inhibitors. ${ }^{[21]}$ 


\section{DDR2 mutation}

The DDR2 gene encodes a cell surface RTK that is mutated to an active form in about $4 \%$ of squamous cell carcinomas of the lung. ${ }^{[22]}$ Dasatinib inhibits DDR2, and one patient treated with the combination of dasatinib and erlotinib had a tumour response. Clinical trials tomdetermine dasatinib efficacy are underway.

\section{MEK1 mutation}

The MAP2K1 gene encodes the MEK1 protein, a central mediator of cell proliferation signals that is downstream of RAF in the MAPK pathway. MAP2K1 mutations may be found in approximately $1 \%$ of adenocarcinomas. ${ }^{[23]}$ The clinical response of NSCLC with MAP2K1 mutation to MEK or ERK inhibitors is currently being investigated.

The accessibility of mutation analysis is limited largely due to the high cost, as well as the lack of quality control, uniformity of techniques and standards among various laboratories. However, the cost for these tests may decrease when the reagents are purchased in bulk. The amount and quality of the tumour tissue used for molecular profiling is also an important issue to consider, especially since the tissue yield for lung cancer samples is limited by small core biopsies. Judicious use of IHC and conservation of samples for molecular testing would be helpful. Cell-free circular tumour DNA is also emerging as a useful tool for mutation testing and therapeutic monitoring.

\section{IMMUNOTHERAPY}

More than $80 \%$ of lung cancer cases are classified as NSCLC. Although there have been significant advances in the treatment of subsets of patients with molecularly defined NSCLC, for instance, NSCLC positive for EGFR mutation and ALK rearrangement, the improvement of prognosis is still modest for the majority of NLCSC patients. It is clear that a plateau has been reached with traditional chemotherapy, with minimal added benefit when chemotherapy is combined with the angiogenesis inhibitor bevacizumab.

Immunotherapeutic approaches are based on the premise that the immune system plays a key role in surveillance and the eradication of malignancy, and tumours evolve in order to elude the immune system. These approaches differ from traditional chemotherapy and targeted therapies that primarily target rapidly dividing cells and key molecular events that drive tumour growth and invasion. The goal of immunotherapy is to help the host's immune system recognize that cancer cells are foreign in order to stimulate immune response.

Historically, non-small cell lung cancer (NSCLC was considered to be non-immunogenic). Two approaches to harness the immune system are of particular interest: immune checkpoint inhibition and vaccination.

\section{IMMUNE ACTIVATION AND CHECKPOINT INHIBITION}

Immune recognition is initiated by antigen presenting cells (APCs). When stimulated by antigens on cancer cells, APCs express B7-1 and B7-2 on their cell surface, and migrate to the lymph nodes to present the antigens to resting $\mathrm{T}$ cells. The B7 proteins bind to CD28 on the T cells, initiating a series of downstream signalling events that promotes the activation, survival and proliferation of the target $\mathrm{T}$ cells. These activated $T$ cells then release cytolytic enzymes such as perforin and granzyme, as well as cytokines that help recruit other members of the immune system to the cancer cells. The result is tumour destruction and the creation of memory $\mathrm{T}$ cells. Several immune checkpoints exist to dampen the immune response to protect healthy individuals from detrimental inflammation and autoimmunity. Two well-characterized checkpoint proteins, the cytotoxic T-lymphocyte antigen 4 (CTLA-4) and the programmed death receptor 1 (PD-1), are targets in NSCLC clinical trials. The purpose of inhibiting these check point proteins is to prevent their interference with the elimination of cancer cells.

\section{Antibodies targeting CTLA-4: ipilimumab}

Ipilimumab is an IgG1 CTLA-4 monoclonal antibody that prolongs overall survival in patients with metastatic melanoma. Currently there is a phase III trial that compares standard chemotherapy with carboplatin and paclitaxel with the same regimen combined with concurrent ipilimumab for patients undergoing chemotherapy for treating naive metastatic squamous cell NSCLC (NCT01285609).

\section{Antibodies targeting PD-1 and PD-L1}

Treatment of NSCLC with antibodies against PD-1 and programmed death-ligand 1 (PD-L1) has yielded encouraging results; early clinical trials showed a prolonged response to the antibody in patients with chemotherapy refractory metastatic NSCLC. Randomized phase III trials to evaluate anti-PD-1 and anti-PD-L1 antibodies for metastatic NSCLC treatment are in progress, and other studies are investigating various combination strategies.

Nivolumab is an IgG4 monoclonal antibody against PD-1 that has been approved for both advanced squamous cell carcinoma of the lung and unresectable or metastatic melanoma. Nivolumab received US Food and Drug Administration approval on March 4, 2015 for the treatment of patients with advanced squamous NSCLC with progression, either in concurrent with or after platinumbased chemotherapy. This approval was based on results from the CheckMate 017 and CheckMate 063 trials.

Pembrolizumab, an IgG4 monoclonal antibody also targeting PD-1, is a breakthrough therapeutic agent for treating advanced NLCLC that received FDA approval in late 2014. The approval was based on emerging results 
from a large Phase I dose expansion trial that have since been updated.

PD-L1 expressed on cancer cells can bind to PD-1 on activated $\mathrm{T}$ cells to suppress the immune system.

MPDL3280A is an IgG1 monoclonal antibody against PD-L1 that targets cancer cells expressing PD-L1, thus preventing the interaction between PD-L1 and PD-1 expressed on activated $\mathrm{T}$ cells. It is also engineered to prevent antibodydependent cell-mediated cytotoxicity (ADCC) and complement mediated cytotoxicity in activated $\mathrm{T}$ cells that may express PD-L1. Similarly, IgG1 monoclonal antibody MEDI4736 and IgG4 monoclonal BMS-936559 also target PD-L1. BMS-936559 is a fully human antibody that is an IgG1 monoclonal antibody to PDL1 with an engineered Fc domain to eliminate MEDI4736 effector function (i.e. complement mediated cytotoxicity and ADCC). BMS936559 is a fully human IgG4 monoclonal antibody to PDL1 which has been evaluated in a dose escalation phase I trial with expansion cohorts in NSCLC, melanoma, and renal cell carcinoma. ${ }^{[24]}$

\section{Vaccination}

Non-small cell lung cancers (NSCLCs) are characterized by several genetic alterations in neoantigens that can potentially be recognized by the immune system as foreign. Vaccination enhances the body's exposure to such antigens and immune cell priming. Randomized trials are currently focusing on approaches that couple tumour antigens or cells with immune adjuvant agents; such approaches may enhance the antigen presenting cell response to the vaccine.

One example is the melanoma associated antigen A3 (MAGE-A3) vaccine. The melanoma associated antigen A3 (MAGE-A3 gene family consists of "cancer germline" or "cancer testis" genes that are normally expressed only on testicular germ cells and placental trophoblasts. ${ }^{[25]}$ Several tumours also express MAGE-A3, including $30-50 \%$ of NSCLCs. The GSK1572932 vaccine is a recombinant MAGE-A3 protein vaccine combined with the immunological adjuvant AS15.

MUC-1 is a cell surface glycoprotein that is overexpressed and/or aberrantly glycosylated in several epithelioid malignancies, including NSCLC. Tecemotide is a vaccine consisting of the BLP25 MUC-1 lipopeptide and the adjuvant monophosphoryl lipid $\mathrm{A}$, as well as cholesterol dimyristoyl phosphatidylglycerol (DMPG) and dipalmitoyl phosphatidylcholine (DPPC) as the carrier lipids that form the liposome. The primary endpoint of the trial evaluating this vaccine was overall survival. There was no significant increase in overall survival among 1239 patients receiving tecemotide compared to those receiving the placebo (median 25.8 and 22.3 months, respectively).

Belagenpumatucel- $\mathrm{L}$ is an allogeneic whole tumour vaccine consisting of cells from four irradiated NSCLC cell lines modified using a TGF-beta antisense plasmid to block TGFbeta secretion. TGF-beta inhibits $\mathrm{T}$ and $\mathrm{B}$ cell activation, dendritic cell maturation and antigen presentation, as well nd natural killer (NK) and lymphokine activated (LAK) activation. TGF-beta also induces immunosuppressive $\mathrm{T}$ regulatory cells.

In addition to the vaccines described above, there are several other types of vaccines that are currently being evaluated in phase III studies. More effort is being invested into developing new vaccines and combining vaccines with other immunologic agents, chemotherapy, or targeted agents. Advances in DNA and RNA sequencing as well as drug development may also ultimately enable the design of personalized vaccines consisting of antigens uniquely expressed by tumour cells from a specific patient.

\section{CONCLUSION}

Lung cancer is the leading cause of cancer-related mortality in the United States and worldwide. More than $80 \%$ of lung cancer cases are classified as NSCLC. In the past decade, there has been significant breakthrough in our understanding of the tumour biology of NSCLC. Signalling pathways that are vital for tumour growth have been identified and have been effectively targeted pharmacologically. This article summarizes the implications of these advances for treating lung cancer and highlights the ongoing work to improve clinical outcomes of this disease. Treatment of lung cancer has come a long way with greater use of molecular markers and targets. Nonetheless, there is still much to be done to help our fight against lung cancer.

\section{Acknowledgments}

Department of Pathology, Army Hospital Reseach and Referrral, New Delhi.

\section{Financial support and sponsorship}

Nil.

\section{Conflicts of interest}

There are no conflicts of interest.

\section{REFERENCES}

1. Brambilla E, Travis WD. Lung cancer. In: World Cancer Report, Stewart BW, Wild CP (Eds), World Health Organization, Lyon 2014.

2. Jemal A, Siegel R, Xu J, Ward E. Cancer statistics, 2010. CA Cancer J Clin 2010;60:277-300.

3. Standfield L, Weston AR, Barraclough H, Van Kooten M, Pavlakis $\mathrm{N}$. Histology as a treatment effect modifier in advanced non-small cell lung cancer: a systematic review of the evidence. Respirology 2011;16:1210-20.

4. Mok TS, Wu Y-L, Thongprasert S, Yang C-H, Chu D-T, Saijo N, Sunpaweravong P, Han B, Margono B, Ichinose Y, Nishiwaki Y, Ohe Y, Yang JJ, Chewaskulyong B, Jiang H, Duffield EL, Watkins CL, Armour AA, Fukuoka M. Gefitinib or carboplatin-paclitaxel in pulmonary adenocarcinoma. N Engl J Med 2009;361:947-57.

5. Mitsudomi T, Morita S, Yatabe Y, Negoro S, Okamoto I, Tsurutani 
J, Seto T, Satouchi M, Tada H, Hirashima T, Asami K, Katakami N, Takada M, Yoshioka H, Shibata K, Kudoh S, Shimizu E, Saito H, Toyooka S, Nakagawa K, Fukuoka M; West Japan Oncology Group. Gefitinib versus cisplatin plus docetaxel in patients with non-smallcell lung cancer harbouring mutations of the epidermal growth factor receptor (WJTOG3405): an open label, randomised phase 3 trial. Lancet Oncol 2010;11:121-8.

6. Zhou C, Wu Y-L, Chen G, Feng J, Liu X-Q, Wang C, Zhang S, Wang J, Zhou S, Ren S, Lu S, Zhang L, Hu C, Hu C, Luo Y, Chen L, Ye M, Huang J, Zhi X, Zhang Y, Xiu Q, Ma J, Zhang L, You C. Erlotinib versus chemotherapy as first-line treatment for patients with advanced EGFR mutation-positive non-smallcell lung cancer (OPTIMAL, CTONG-0802): a multicentre, open-label, randomised, phase 3 study. Lancet Oncol 2011;12:735-42.

7. Sahoo R, Harini VV, Babu VC, Patil Okaly GV, Rao S, Nargund A, Venkataswamy E, Rao R, Kumar BS. Screening for EGFR mutations in lung cancer, a report from India. Lung Cancer 2011;73:316-9.

8. Soda M, Choi YL, Enomoto M, Takada S, Yamashita Y, Ishikawa S, Fujiwara S, Watanabe H, Kurashina K, Hatanaka H, Bando M, Ohno S, Ishikawa Y, Aburatani H, Niki T, Sohara Y, Sugiyama Y, Mano H. Identification of the transforming EML4- ALK fusion gene in nonsmall-cell lung cancer. Nature 2007;448:561-6.

9. Camidge DR, Bang Y-J, Kwak EL, Iafrate AJ, Varella-Garcia M, Fox SB, Riely GJ, Solomon B, Ou SH, Kim DW, Salgia R, Fidias P, Engelman JA, Gandhi L, Jänne PA, Costa DB, Shapiro GI, Lorusso P, Ruffner K, Stephenson P, Tang Y, Wilner K, Clark JW, Shaw AT. Activity and safety of crizotinib in patients with ALK-positive nonsmall-cell lung cancer: updated results from a phase 1 study. Lancet Oncol 2012;13:1011-9.

10. Lindeman NI, Cagle PT, Beasley MB, Chitale DA, Dacic S, Giaccone G, Jenkins RB, Kwiatkowski DJ, Saldivar JS, Squire J, Thunnissen E, Ladanyi M. Molecular testing guideline for selection of lung cancer patients for EGFR and ALK tyrosine kinase inhibitors: guideline from the College of American Pathologists, international association for the study of lung cancer, and Association for Molecular Pathology. Arch Pathol Lab Med 2013;137:828-60.

11. Leighl NB, Rekhtman N, Biermann WA, Huang J, Mino-Kenudson M, Ramalingam SS, West H, Whitlock S, Somerfield MR. Molecular Testing for selection of patients with lung cancer for epidermal growth factor receptor and anaplastic lymphoma kinase tyrosine kinase inhibitors: American Society of Clinical Oncology Endorsement of the College of American Pathologists/International Society for the study of lung cancer/Association of Molecular Pathologists Guideline. J Clin Oncol 2014;32:3673-9.

12. Balak MN, Gong Y, Riely GJ, Somwar R, Li AR, Zakowski MF, Chiang A, Yang G, Ouerfelli O, Kris MG, Ladanyi M, Miller VA, Pao W. Novel D761Y and common secondary T790M mutations in epidermal growth factor receptor-mutant lung adenocarcinomas with acquired resistance to kinase inhibitors. Clin Cancer Res 2006;12:6494-501.

13. Engelman JA, Zejnullahu K, Mitsudomi T, Song Y, Hyland C, Park JO, Lindeman N, Gale CM, Zhao X, Christensen J, Kosaka T, Holmes AJ, Rogers AM, Cappuzzo F, Mok T, Lee C, Johnson BE, Cantley LC, Jänne PA. MET amplification leads to gefitinib resistance in lung cancer by activating ERBB3 signaling. Science 2007;316:1039-43.

14. Cappuzzo F, Marchetti A, Skokan M, Rossi E, Gajapathy S, Felicioni L, Del Grammastro M, Sciarrotta MG, Buttitta F, Incarbone M, Toschi L, Finocchiaro G, Destro A, Terracciano L, Roncalli M,
Alloisio M, Santoro A, Varella-Garcia M. Increased MET gene copy number negatively affects survival of surgically resected non-smallcell lung cancer patients. J Clin Oncol 2009;27:1667-74.

15. Bergethon K, Shaw AT, Ou SH, Katayama R, Lovly CM, McDonald NT, Massion PP, Siwak-Tapp C, Gonzalez A, Fang R, Mark EJ, Batten JM, Chen H, Wilner KD, Kwak EL, Clark JW, Carbone DP, Ji H, Engelman JA, Mino-Kenudson M, Pao W, Iafrate AJ. ROS1 rearrangements define a unique molecular class of lung cancers. $J$ Clin Oncol 2012;30:863-70.

16. Zinner RG, Glisson BS, Fossella FV, Pisters KM, Kies MS, Lee PM, Massarelli E, Sabloff B, Fritsche HA Jr, Ro JY, Ordonez NG, Tran HT, Yang Y, Smith TL, Mass RD, Herbst RS. Trastuzumab in combination with cisplatin and gemcitabine in patients with Her2-overexpressing, untreated, advanced non-small cell lung cancer: report of a phase II trial and findings regarding optimal identification of patients with Her2-overexpressing disease. Lung Cancer 2004;44:99-110.

17. Kinno T, Tsuta K, Shiraishi K, Mizukami T, Suzuki M, Yoshida A, Suzuki K, Asamura H, Furuta K, Kohno T, Kushima R. Clinicopathological features of nonsmall cell lung carcinomas with BRAF mutations. Ann Oncol 2014;25:138-42.

18. Ichimura E, Maeshima A, Nakajima T, Nakamura T. Expression of c-met/HGF receptor in human non-small cell lung carcinomas in vitro and in vivo and its prognostic significance. Jpn J Cancer Res 1996;87:1063-9.

19. Kohno T, Ichikawa H, Totoki Y, Yasuda K, Hiramoto M, Nammo T, Sakamoto H, Tsuta K, Furuta K, Shimada Y, Iwakawa R, Ogiwara H, Oike T, Enari M, Schetter AJ, Okayama H, Haugen A, Skaug V, Chiku S, Yamanaka I, Arai Y, Watanabe S, Sekine I, Ogawa S, Harris CC, Tsuda H, Yoshida T, Yokota J, Shibata T. KIF5B-RET fusions in lung adenocarcinoma. Nat Med 2012;18:375-7.

20. Rekhtman N, Paik PK, Arcila ME, Tafe LJ, Oxnard GR, Moreira AL, Travis WD, Zakowski MF, Kris MG, Ladanyi M. Clarifying the spectrum of driver oncogene mutations in biomarker-verified squamous carcinoma of lung: lack of EGFR/KRAS and presence of PIK3CA/AKT1 mutations. Clin Cancer Res 2012;18:1167-76.

21. Heist RS, Mino-Kenudson M, Sequist LV, Tammireddy S, Morrissey L, Christiani DC, Engelman JA, Iafrate AJ. FGFR1 amplification in squamous cell carcinoma of the lung. J Thorac Oncol 2012;7:1775-80.

22. Heist RS, Sequist LV, Engelman JA. Genetic changes in squamous cell lung cancer: a review. $J$ Thorac Oncol 2012;7:924-33.

23. Marks JL, Gong Y, Chitale D, Golas B, McLellan MD, Kasai Y, Ding L, Mardis ER, Wilson RK, Solit D, Levine R, Michel K, Thomas RK, Rusch VW, Ladanyi M, Pao W. Novel MEK1 mutation identified by mutational analysis of epidermal growth factor receptor signaling pathway genes in lung adenocarcinoma. Cancer Res 2008;68:5524-8.

24. Rizvi NA, Shepherd FA, Antonia SJ, Brahmer JR, Chow LQ, Goldman J, Juergens R, Borghaei H, Ready NE, Gerber DE, Shen Y, Harbison C, Chen AC, Gettinger S. First-Line Monotherapy With Nivolumab (Anti-PD-1; BMS-936558, ONO-4538) in Advanced Non-Small Cell Lung Cancer (NSCLC): Safety, Efficacy, and Correlation of Outcomes With PD-L1 Status. Poster 165, Chicago Multidisciplinary Symposium in Thoracic Oncology (CMSTO) Annual Meeting, 2014;90:S31.

25. Sienel W, Varwerk C, Linder A, Kaiser D, Teschner M, Delire M, Stamatis G, Passlick B. Melanoma associated antigen (MAGE)-A3 expression in Stages I and II non-small cell lung cancer: results of a multi-center study. Eur J Cardiothorac Surg 2004;25:131-4. 